J. $\mathrm{ZYCH}^{*}$

\title{
PULSATING GAS DOSAGE IN THE MOULDING SANDS HARDENING PROCESS IN THE COLD-BOX TECHNOLOGY
}

\author{
PULSACYJNE DOZOWANIE GAZU W PROCESIE UTWARDZANIA MAS W TECHNOLOGII COLD-BOX
}

\begin{abstract}
The results of investigations of the moulding sands hardening process in the cold-box technology - with an application of two ways of gas dosage - are presented in the paper. A new, ultrasound method of testing the kinetics of hardening of moulding sands with chemical binders was applied. Moulding sands with phenol-formaldehyde resin and moulding sands with water-glass hardened by $\mathrm{CO}_{2}$, were subjected to investigations. A continuous gas dosage was substituted by the pulsating one. It was shown, that the change of the dosage mode could lead to decreasing the gas consumption (even several times). In addition, it was found that the pulsating way of dosage provides improvements of moulding sands technological properties, mainly strength. Investigations concerned the cold-box processes, in which one or two technological gases were used.

Keywords: cold-box, ultrasounds, moulding sand hardening, pulsating flow
\end{abstract}

W pracy przedstawiono wyniki badań procesu utwardzania mas w technologii cold-box z zastosowaniem dwóch sposobów dozowania gazu. Zastosowano nową, ultradźwiękowa metodę badań kinetyki utwardzania mas wiązany spoiwami chemicznymi. Badaniami objęto masy z żywica fenolowo-formaldehydowa i masy ze szkłem wodnym utwardzane $\mathrm{CO}_{2}$. Zastąpiono dozowanie ciągłe gazu dozowaniem pulsacyjnym. Wykazano, że zmiana sposobu dozowania gazu może prowadzić nawet do kilkukrotnego obniżenia jego zużycia. Stwierdzono ponadto, iż pulsacyjne dozowanie gazu prowadzi do poprawy właściwości technologicznych mas, głównie wytrzymałości. Badania dotyczyły procesów cold - box, w których wykorzystuje się jeden bądź dwa technologiczne gazy.

\section{Introduction}

The technology of hardening of moulding sands with chemical binders by active gases, known as the cold-box process, requires a multi-parameter optimisation. The chemical reaction between a binder and gaseous hardener is very fast in the grained medium, which is a good point of this technology. Binders distributed on matrix grains form a highly developed surface. A binder layer is the most often of a few micrometers thickness $[1,2,7]$. Due to this small thickness a gaseous hardener travelling in intergranular capillaries reacts with a binder material spread on grains nearly simultaneously in the whole binder volume. In effect the moulding sand hardening is very fast. The variant of the active gas continuous dosage dominates in the current solutions of the cold-box technology [1]. The time of dosage called often the 'blowing through' time in dependence of the binder kind and core size lasts from a dozen or so to a few hundred seconds. Solutions in which the gas dosage is applied with periodical pauses can be also found. Still another variant of the cold-box process, presently the most often applied, is blowing into the hardened moulding sand the gas acting as a chemical reaction catalyst (amine compounds) [2]. At the end of this process, the air blowing through the moulding sand is applied in order to 'rinse out' amine from the produced core. However, there is a lack of solutions in which a gas dosage would be done in a technique of short pauses (from 1 to a few seconds). Such way should be qualified as a pulsating gas dosage. A development of automatics allows to solve this problem in several technical ways. Implementation of the pulsating dosage can lead to many advantageous effects: gas consumption limitation, improvement of technological moulding sands parameters, avoiding casting defects and many others.

\section{Idea of the pulsating gas dosage in the cold-box technology}

A certain solution, of looking for the optimal way of the active gas blowing, can be the pulsating way, in which after a short period of gas blowing either a pause occurs or a mould is blown by a neutral gas, e.g. air. The cycle is repeated several times until the needed degree of the moulding sand hardening is achieved. The idea of such way of blowing is based on the assumption that the moulding sand hardening in the selected layer of a thickness $\mathbf{d x}$ lasts slightly longer than the gas blowing. Therefore after supplying a gas portion - sufficient for hardening of the dx layer - a certain 'waiting' is needed until the hardening process obtains the sufficient 
level. At the pulsating gas dosage the pressure impulses can improve conditions of its flowing due to 'opening' new channels formed by irregular (in shapes and diameters) capillaries. At the pulsating dosage there is a possibility of controlling the gas amount introduced into the mould (core). At a continuous blowing the process is being performed for as long as the active gas reaches the most distant layers, it means until it passes a distance $X_{\text {cal }}$ (Fig.1). The amount of gas introduced in this period into the moulding sand can be too large. The authors [3] are of the opinion that the gas consumption is often 5-7 times too large in relation to stoichiometric calculations. At the continuous gas dosage the hardening comprises simultaneously large moulding sand volumes (dx layer is wide). At the pulsating gas dosage the hardening, in the given moment, occurs in a small volume ( $\mathbf{d x}$ layer is narrow), and the binding process is rather of a layered character.

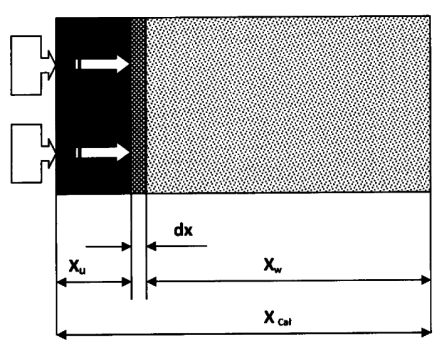

Fig. 1. Model of the moulding sand hardening process at the active gas blowing: $\mathrm{X}_{u}$ - hardened layer, $\mathrm{d}_{x}$ - layer, in which the hardening process lasts, $X_{w}-$ not hardened layer, $X_{\text {cał }}-$ total thickness of the hardened layer

\section{Investigations of the hardening kinetics}

Investigations of the moulding sands hardening were carried out by ultrasound methods [2,4,9 - 13]. The method, developed in the last years, provides investigation possibilities in the field of monitoring hardening processes of moulding sands as well as investigating similar processes in other materials with chemical binders, e.g. in concretes [5]. The hardening gas $\left(\mathrm{CO}_{2}\right)$ is blown through the moulding sand sample of dimensions $50 \times 100 \times 100 \mathrm{~mm}$, compacted in the tester. Simultaneously a longitudinal ultrasound wave is transferred through this sample. The transition time of the wave impulse through the moulding sand being hardened is recorded continuously. A complex physical and chemical hardening process causes viscoelastic changes in moulding sands. Changes of rheological properties of the binder cause the ultrasound wave velocity increase.

\subsection{Moulding sands binding, technology with using one kind of a gas}

The process of sands hardening in the cold - box technology can be based on an application of one kind of a gas, which acts as a hardener. It can be also based on an application of two gases, out of which one acts as a hardener or catalyst, while another is the most often used for the moulding sand purification from left-over of active gases.

\subsubsection{Moulding sands hardening at the continuous gas dosage}

The obtained results of two kinds of moulding sands applied in the cold-box technology aimed at the determination differences in hardness rates, at the continuous dosage of $\mathrm{CO}_{2}$, are shown in Figures 2 and 3.

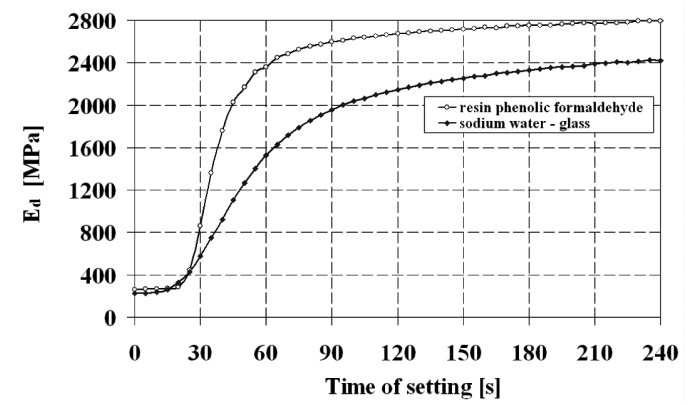

Fig. 2. Pathways of the hardening of the moulding sand with water-glass and moulding sand with phenol-formaldehyde resin, at continuous blowing of $\mathrm{CO}_{2}$

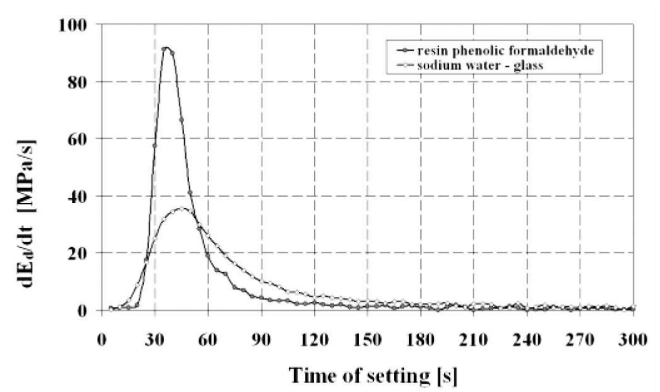

Fig. 3. Kinetics of the hardening of the moulding sand with water-glass and moulding sand with phenol-formaldehyde resin, at continuous blowing of $\mathrm{CO}_{2}$

The moulding sand with water-glass contained $3.0 \%$ of a binder (glass 145), while the one with phenolic resin contained $2.5 \%$ of a binder. The hardening rate of the moulding sand with water-glass, measured by modulus of elasticity increments, is nearly three times lower than for the sand with phenol-formaldehyde resin. The dynamic modulus of elasticity $\mathrm{E}_{d}$ - in ultrasound examinations - is calculated as the product of an apparent moulding sand density and a square of the longitudinal wave velocity $[2,4]$.

\subsubsection{Moulding sands hardening at the pulsating gas dosage}

At the pulsating dosage of active gas, abrupt pressure increases are observed in micro-spaces of the blown through moulding sand. After these increases, due to a gas consumption, a continuous pressure decrease is observed until 'underpressure' occurs [5 ]. However, pressure oscillations do not mean the concentration changes. At the constant reagent concentration the instantaneous rate of the chemical reaction leading to the binder cross-linking (hardening) should be similar to the rate, which is observed at the continuous gas flow. In order to verify this proposition the measurements of the kinetics of moulding sands hardening at the continu- 
ous and pulsating dosage of the active gas $-\mathrm{CO}_{2}$ were performed. Investigations were carried out for the moulding sand with phenol-formaldehyde resin, hardened by carbon dioxide $\left(\mathrm{CO}_{2}\right)$. The results of these investigations are shown in Figure 4. Instantaneous process rates, measured by modulus $\mathrm{E}_{d}$ (Fig. 4) increments, are very similar. In case of the pulsating gas dosage, only the start of the hardening in the investigated moulding sand layer $(\mathrm{dx})$ is delayed.

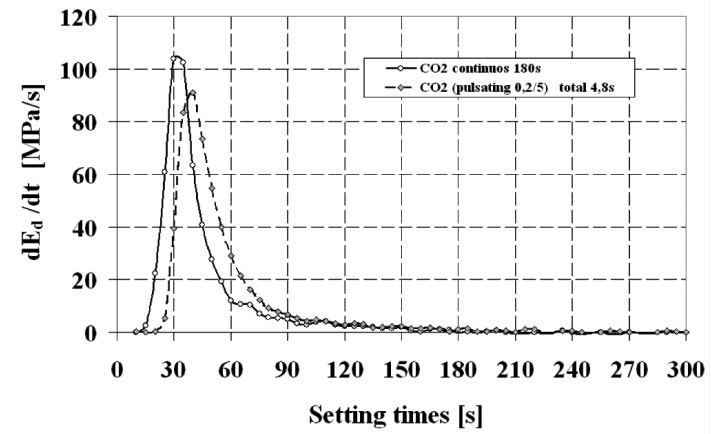

Fig. 4. Rates of hardening of the moulding sand with phenol-formaldehyde resin at the continuous and pulsating dosage of $\mathrm{CO}_{2}$

\subsubsection{Moving of the hardening front at the continuous and pulsating gas dosage}

The rate of moving the moulding sand hardening front (layer dx- in Fig. 1) can be determined from Equation 1, provided that the flowing gas is not consumed during its flow. Such situation occurs in the cold - box process when amine compounds are used as a catalyst, which is not consumed in the process. In the remaining variants of the cold - box process, the sand hardening leads to the flowing gas consumption. Therefore calculations of moving rates of the gas stream front can not be done on the grounds of Equation 1 [8]. These calculation must be performed on the grounds of the experimental results.

$$
Q=\frac{n \Delta p \pi \cdot r^{4}}{8 \cdot \eta \cdot l}
$$

$\mathrm{Q}$ - flow rate of a liquid or gas,

$\eta$ - viscosity of a liquid or gas,

$\mathrm{n}$ - number of capillaries,

1 - length of capillaries, $r$ - average capillary radius, $\Delta \mathrm{p}$ - pressure difference.

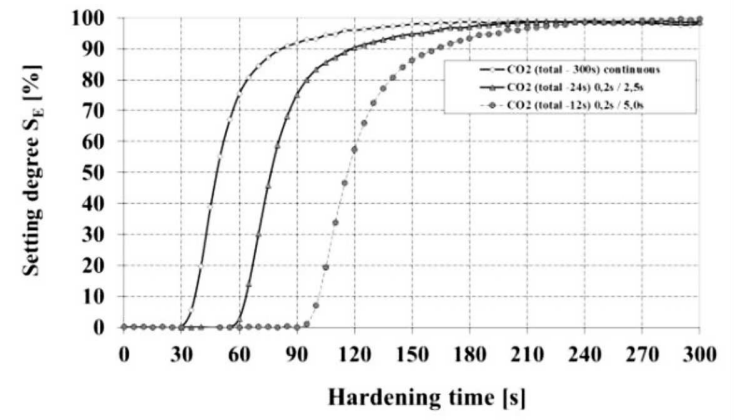

Fig. 5. Pathways of hardening the moulding sand with phenol-formaldehyde resin at the continuous and cyclic dosage of the active gas $\left(\mathrm{CO}_{2}\right)$
Investigations of the kinetics of the moulding sand hardening in the core box of dimensions $50 \times 150 \times 300 \mathrm{~mm}$ were carried out. The gas flow was realized in a unidirectional system with the dosage performed from the upper core box surface, along the core axis. To enable a free gas flow the bottom core box surface was made of a net.

Measuring heads were placed at a distance of $220 \mathrm{~mm}$ from the gas dosage surface. The 'blow through' process was performed at a uniform gas $\left(\mathrm{CO}_{2}\right)$ pressure being $0.1 \mathrm{MPa}$. The obtained results are presented in Figure 6 . At the continuous blowing of $\mathrm{CO}_{2}$, at a distance of $220 \mathrm{~mm}$ from the surface the hardening process starts after $\sim 30$ seconds. The pulsating dosage in a cycle: $0.2 \mathrm{~s}$ blow- $2.5 \mathrm{~s}$ pause allows to start the hardening process after $\sim 60$ seconds. A further prolongation of pauses causes a time prolongation before the hardening process starts. When the front of the molding sand hardening reaches the measuring zone the hardening process proceeds with the similar rate, regardless of the dosage mode.

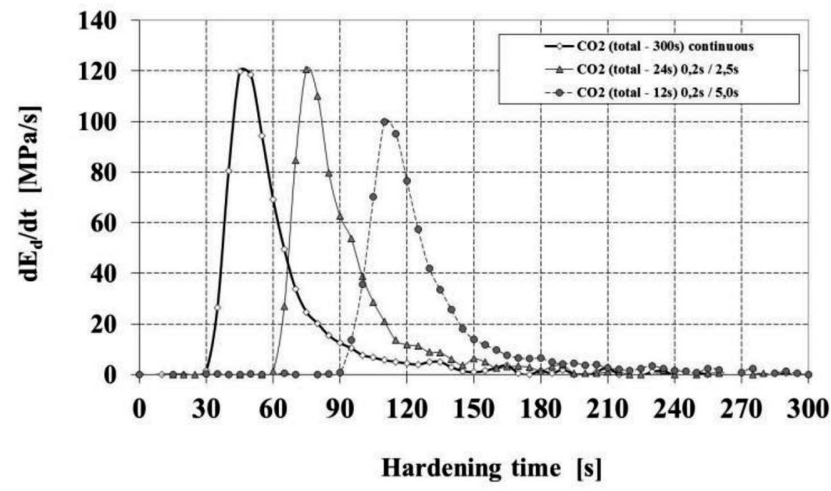

Fig. 6. Hardening rates of moulding sand with phenol-formaldehyde resin at a distance of $220 \mathrm{~mm}$ from the blowing surface at the continuous and pulsating $\mathrm{CO}_{2}$ dosage

On the grounds of investigations, which results are presented in Figures 6, calculations of the average moving rate of the hardening front. If at the continuous dosage the front moving rate equals $v_{\max }$, at the pulsating dosage it is smaller. Thus, when the pulsating blow time fraction is slightly below 0.1 of the continuous blow time $\left(\tau_{\text {cal }}\right)$ the front moving rate is $0.40 v_{\text {max }}$, and when the pulsating blow time equals $0.25 \tau_{\text {cat }}-$ this rate is $0.65 v_{\max }$. However, a lack of a proportional dependence between shortening of the blowing time and decreasing of the hardening front moving rate can be noticed.

\subsection{Pathways of moulding sands binding with an application of two kinds of gases}

The moulding sands hardening in the cold-box technology with using two kinds of gases, being dosed in a determined sequence, is currently applied in the classic amine process. Hardening of moulding sands with organic binders is always of a complex physical and chemical character. This means that both chemical (binder-hardener reactions) and physical processes, such as evaporating of liquid components of a binder. Supplying of active or catalysing gas is necessary for chemical processes while for physical processes (drying or 'rinsing out' of amines) a flow of neutral gas e.g. air, is needed. In a certain variant of the cold-box technology with using 
two kinds of gases the pulsating technique and alternate dosage can be also applied. The results of investigations performed for moulding sands with water-glass hardened by $\mathrm{CO}_{2}$ and having air additionally being blown through, confirm this conclusion. The control module was alternately opening valves with $\mathrm{CO}_{2}$ and with compressed air. Valve opening times were selected in a wide range of proportions. Changes pathways described by $\mathrm{E}_{d}$ module are shown in Figure 7 . The moulding sand hardened by $\mathrm{CO}_{2}$ (without air) being blown through, either in the continuous or pulsating mode occurs fast, however the module values of the hardened moulding sand are rather low $(\sim 3.000 \mathrm{MPa})$. When an additional, pulsating air blowing is applied the hardening time is longer but $\mathrm{E}_{d}$ module is nearly $50 \%$ higher $(\sim 4.500 \mathrm{MPa})$.

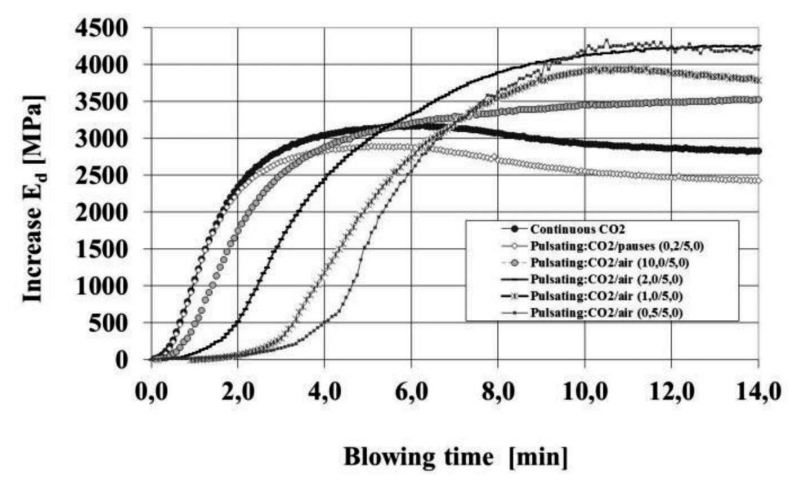

Fig. 7. Hardening pathways of the moulding sand with water-glass at alternate applying pulsating dosage of two gases: $\mathrm{CO}_{2}$ and air

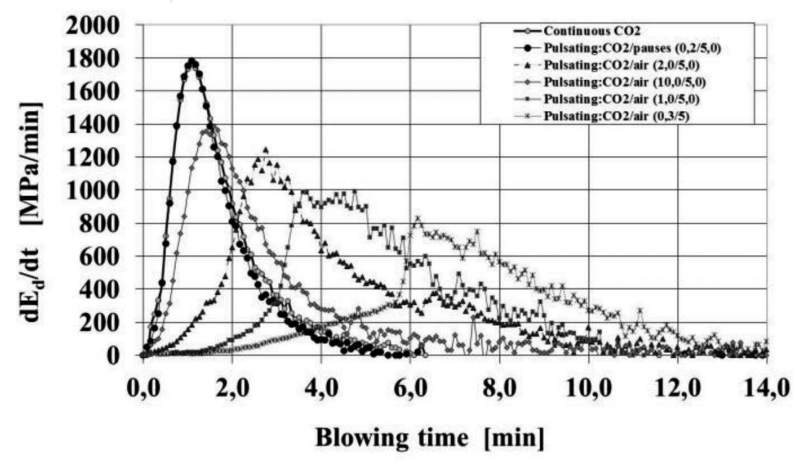

Fig. 8. Pathways of hardening moulding sand with water-glass at the pulsating, alternate dosage of the gas $\left(\mathrm{CO}_{2}\right)$ and air

Pulsating and alternating air introduction causes decreasing $\mathrm{CO}_{2}$ concentration in the gas being in contact with water-glass. A decreased concentration of one of the chemical reaction reagent leads to decreasing the reaction rate. This decreased reaction rate, and indirectly decreased hardening rate, measured by derivative value: $\mathrm{dE}_{d} / \mathrm{dt}$, is seen in Figure 8 . Thus, by selecting the blowing through times of $\mathrm{CO}_{2}$ and air, it is possible to control hardening rates and times. Hardening rates of moulding sands with water-glass decides on the quality and structure of binder bridges joining matrix grains. When this hardening is fast numerous cracks of bridges occur. Moulding sands being hardened under such conditions are characterised by worse technological properties, mainly by a lower strength. Along with an increase of the hardening rate of moulding sand with water-glass the dynamic module $\mathrm{E}_{d}$ value decreases as well as the moulding strength decreases since it 'follows' this module value, as indicated the previous works of the author [2].

\section{Conclusions}

The performed investigations allow to draw the following conclusions:

- Pulsating gas dosage provides the possibility of relatively large savings in its consumption. The obtained results indicate that these savings can reach $\sim 70-80 \%$.

- The change of the gas dosage mode from continuous to pulsating, at maintaining the optimal proportion of blowing/pause times in a cycle, causes only insignificant slowing down of the average hardening front rate in the moulding sand.

- Optimisation of mutual relations blow/pause in the pulsating dosage cycle can be obtained on the basis of the ultrasound monitoring of the binding process.

- Some binders, especially moulding sands with water-glass, are sensitive to too high hardening rates and excessive drying, which is seen as a strength loss. The pulsating mode of the gas dosage provides, for this group of binders, the possibility of achieving much better strength parameters of moulding sands.

\section{REFERENCES}

[1] J.L. Le w a n d ow ski, Materiały formierskie, WNT, Warszawa (1971).

[2] J. Z y c h, Synthesis of the Ultrasonic Technique Applications to Kinetics of the Selected Processes Occurring in Moulding Materials, Monographs, AGH - Cracow, (2007).

[3] E. Fle ming, W. Tilch, T. S chuster, M. Iv a nov, Patent DE 4312939 A 1. 27. X. (1994).

[4] J. Zy c h, Patent PL 192202 B1 29.07.(1999).

[5] J. Zy ch, Cement Wapno Beton ISSN-1425-8129, 1, 5-16 (2006).

[6] J. Z y c h, Ł. J a m r o z ow i c z, Archives of Metallurgy and Materials 55 (3), 963 (2010).

[7] D. B o e n i s c h, Giesserei 70, 4, 97-106 (1983).

[8] H. D a r c y, Les Fontainespubliques de la ville de Dijon, Dalmont, Paris, (1856).

[9] J. Z y c h, Giesserei Rundschau 47, 1/2, 10-14 (2000).

[10] J. Zy ch, Giesserei -Erfahfungsaustausch 44, 4, 221-226 (2000).

[11] J. Z y c h, Acta Metallurgica Slovaca 7, 3, 141-147 (2001).

[12] J. Zych, Archiwum Tech. Maszyn i Aut., Poznań 21, 1, 161-169 (2001).

[13] J. Z y c h, Archives of Foundry Engineering 1, 1, 586-593 (2001).

This article was first presented at the VI International Conference "DEVELOPMENT TRENDS IN MECHANIZATION OF FOUNDRY PROCESSES”, Inwałd, 5-7.09.2013 